\title{
Panorama actual en el diagnóstico de la tuberculosis cutánea
}

\author{
J. Almaguer-Cháveza, J. Ocampo-Candiania y A. Rendón ${ }^{b}$

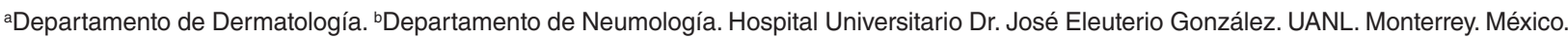

Resumen. La tuberculosis pulmonar y cutánea está causada por Mycobacterium tuberculosis. Según datos de la Organización Mundial de la Salud (OMS) se presentan alrededor de 8 millones de casos nuevos al año. La incidencia de la tuberculosis cutánea se ha incrementado paralelamente con la de la tuberculosis pulmonar. La coinfección de $M$. tuberculosis y el virus de la inmunodeficiencia humana (VIH) se considera una de las principales causas. Los métodos diagnósticos utilizados en la actualidad para la identificación de tuberculosis tanto pulmonar como extrapulmonar dejan un amplio margen de error, retrasando el inicio de un tratamiento oportuno. Presentamos una revisión de dichos métodos y de su aplicación en las formas cutáneas. En conclusión, los hallazgos histopatológicos y el aislamiento de $M$. tuberculosis en cultivos de biopsias o por reacción en cadena de la polimerasa (PCR) son las herramientas diagnósticas más útiles para la tuberculosis cutánea.

Palabras clave: tuberculosis cutánea, diagnóstico, micobacteriosis.

\begin{abstract}
CURRENT PANORAMA IN THE DIAGNOSIS OF CUTANEOUS TUBERCULOSIS
Abstract. Pulmonary and cutaneous tuberculosis are caused by Mycobacterium tuberculosis. According to data from the World Health Organization, there are around 8 million new cases per year. The incidence of cutaneous tuberculosis has risen in parallel with that of pulmonary tuberculosis, and coinfection by $M$ tuberculosis and human immunodeficiency virus is considered to be one of the main causes. Current diagnostic methods for pulmonary and extrapulmonary tuberculosis are far from perfect, leading to a delay in starting appropriate therapy. We present a review of these diagnostic methods and of their use in the cutaneous forms. In conclusion, histopathologic findings and isolation of $M$ tuberculosis in cultures of biopsy material or by polymerase chain reaction are the most useful diagnostic tools in cutaneous tuberculosis.
\end{abstract}

Key words: cutaneous tuberculosis, diagnosis, mycobacteriosis.

\section{Introducción}

La tuberculosis (TB) es un problema de salud pública a nivel mundial con grandes repercusiones y no sólo se limita a países en vías de desarrollo. Según la Organización Mundial de la Salud (OMS), cada año se presentan alrededor de 8 millones de casos nuevos y se calcula que existen 1.700 millones de personas infectadas. La TB pulmonar (TBP) ocupa el quinto lugar como causa de muerte a nivel mundial, ocasionando tres millones de muertes anuales. Hasta el $95 \%$ de los casos de TBP se reportan en países en vías de desarrollo ${ }^{1}$. Las formas extrapulmonares, incluyendo la TB cutánea (TBC) representan el 10-20\% de todos los casos. La TBC causa alrededor del 1,5\% de todas las

Correspondencia:

Jorge Ocampo-Candiani.

Madero y Gonzalitos, s/n

Mitras Centro 64460. Monterrey. México.

jocampo2000@yahoo.com.mx

Aceptado el 5 de diciembre de 2008. formas de TB y es responsable del 0,1 al 1\% de todos los desórdenes cutáneos ${ }^{2,3}$. La TBP mostró una incidencia a la baja durante el siglo xx. Sin embargo, a partir de la década de los ochenta y hasta la actualidad, el número de casos ha ido en aumento. La incidencia de TBC ha mostrado el mismo comportamiento. El sida, la aparición de cepas de Mycobacterium tuberculosis (Mtb) resistentes y el incremento en el uso de fármacos inmunosupresores son algunos de los responsables de este fenómeno ${ }^{1,4-7}$.

La falta de un diagnóstico oportuno ha sido otro factor importante que ha dificultado su control. El desarrollo de nuevas herramientas diagnósticas es uno de los componentes del Plan Mundial para Detener la Tuberculosis 2006-2015 y de la Nueva Estrategia Mundial para Detener la TB de la OMS, donde apoyan la medicina basada en la evidencia para el desarrollo de nuevas políticas en el diagnóstico de la TB. Como dato interesante, el mundo gasta alrededor de un billón de dólares (EUA) al año en el diagnóstico de la TB ${ }^{1,7}$.

Los métodos diagnósticos disponibles van desde los muy simples y económicos hasta los muy complejos y cos- 
tosos. Entre los primeros se encuentra la tradicional baciloscopia en el esputo, que aunque es el más usado tiene una baja sensibilidad y una especificidad variable. Los procedimientos más sofisticados, como los que usan la biología molecular, son muy específicos pero costosos y con sensibilidad variable; estos factores limitan su uso en los países de bajos recursos. La gran mayoría de los procedimientos diagnósticos disponibles tienen su mayor utilidad en la $\mathrm{TBP}^{8}$. El objetivo de este trabajo es revisarlos y describir cómo pueden utilizarse en el diagnóstico de la TBC.

\section{Etiología y patogenia}

La TBP y la TBC están ocasionadas por Mtb y ocasionalmente por M. bovis. La infección habitualmente se adquiere por inhalación de la micobacteria, pero también puede ocurrir por ingestión o inoculación. La piel intacta provee una barrera efectiva contra la invasión por el microorganismo, pero cualquier solución de continuidad en la barrera mucocutánea facilita la entrada del mismo y, por tanto, de la infección. Posterior a la inhalación de los bacilos tuberculosos, aquellos contenidos en partículas aerógenas de 1-5 $\mu$ de diámetro son capaces de alcanzar el alveolo pulmonar y producir la infección pulmonar primaria, y de ahí su posible diseminación para producir las formas extrapulmonares, incluyendo la cutánea. La TBC puede ocurrir además por inoculación directa o por contigüidad con lesiones en otros tejidos como los ganglios, el hueso, el tubo digestivo, la pleura y el mismo pulmón.

La infección desencadena en el huésped una respuesta inmune de hiperreactividad celular tardía, responsable de las manifestaciones clínicas e histológicas, que tarda de 2-10 semanas en desarrollarse completamente y se revela por la aparición de una reacción tuberculínica positiva. Sólo el $5 \%$ de los infectados desarrollarán TB primaria ${ }^{6}$. En un $10 \%$ de los infectados se producirá la enfermedad meses o años después por reactivación de bacilos en estado latente, produciendo así la forma de TB en la que se detectan la mayoría de los casos, la TBP de reactivación (postprimaria $)^{6}$. Esta última presentación es la contagiosa. El potencial de infectividad de un paciente con TBP depende básicamente de la cantidad de bacilos que contienen sus secreciones y de la frecuencia de la tos. La posibilidad de contagiarse dependerá del estado de inmunidad del huésped expuesto y de lo frecuente que sea la exposición. Una persona con TBP arroja micobacterias al medio ambiente en sus secreciones respiratorias, pero la luz ultravioleta del sol las mata rápidamente. En condiciones de baja ventilación y poca luz solar, los bacilos suspendidos en el aire son viables durante 3-5 días, creando así la ocasión para que sean inhalados por otra persona ${ }^{6}$. Los mecanismos de transmisión de la TBP y sus manifestaciones clínicas nos competen, ya que algunos de los casos de TBC se presentan de manera simultánea con TBP o con antecedentes de la misma. La TBC raramente es primaria.

\section{Tuberculosis cutánea}

La TBC ofrece un reto diagnóstico: las manifestaciones son diversas, las lesiones dermatológicas típicas son raras y la identificación del bacilo en tinciones o cultivos es inusual. La afección cutánea puede ocurrir por infección de la piel de manera aislada o en conjunto con infección en otros órganos, es decir, como TB diseminada. La tabla 1 resume las principales características de cada una de estas formas de presentación de la TBC. Las lesiones causadas por inoculación directa de una fuente externa suelen manifestarse como chancro tuberculoso, TB verrugosa (fig. 1) y, ocasionalmente, como lupus vulgaris. La afectación cutánea desde una fuente endógena puede aparecer como escrofuloderma (fig. 2), TB miliar aguda, TB gomosa, lupus vulgaris y TB orificial. Esta última usualmente se observa en pacientes con afección pulmonar, intestinal o anogenital, siendo la boca el sitio más frecuentemente afectado ${ }^{9,10}$. El lupus vulgar es la forma clínica más frecuente de TBC en países industrializados, hasta el $40 \%$ de los pacientes presentan linfadenitis tuberculosa asociada y el 10-20\% de los casos se asocian a TBP $u$ ósea y se supone que son estos los focos de infección primaria ${ }^{3,4,11-13}$. Sin embargo, el tipo escrofuloderma es el que se asocia con más frecuencia con TBP activa ${ }^{4}$.

Además de las lesiones infecciosas se pueden presentar erupciones cutáneas secundarias no a infección, sino a fenómenos inmunes generados por la infección a distancia. Estas lesiones se llaman tubercúlides y existen tres variedades: papulonecróticas, liquen escrofulosum y eritema indurado ${ }^{9,10}$. El diagnóstico de la TBC se complica al considerar los posibles diagnósticos diferenciales: lesiones por micobacteriosis atípicas u otras dermatosis infecciosas (sífilis, esporotricosis, cromomicosis, actinomicosis), acné conglobata por mencionar algunas ${ }^{11}$. La presentación clínica no suele ser suficiente para un diagnóstico preciso: las lesiones despiertan la sospecha clínica, pero es necesario confirmar el diagnóstico con pruebas complementarias. Las manifestaciones sistémicas características de la TBP, como fiebre y pérdida de peso, son inusuales en las formas cutáneas. Su presencia debe orientar hacia una enfermedad sistémica. De la misma forma, la presencia de síntomas respiratorios como tos y hemoptisis sugerirán la presencia de enfermedad pulmonar coexistente. En estos casos se debe dirigir los esfuerzos diagnósticos a la infección en el pulmón, ya que la identificación es más fácil y la afección cutánea se diagnosticaría por inferencia. En pacientes con infección por el virus de la inmunodeficiencia humana (VIH) y otras formas de inmunosupresión las lesiones cutáneas más frecuentes incluyen la forma miliar asociada o no a nódulos 


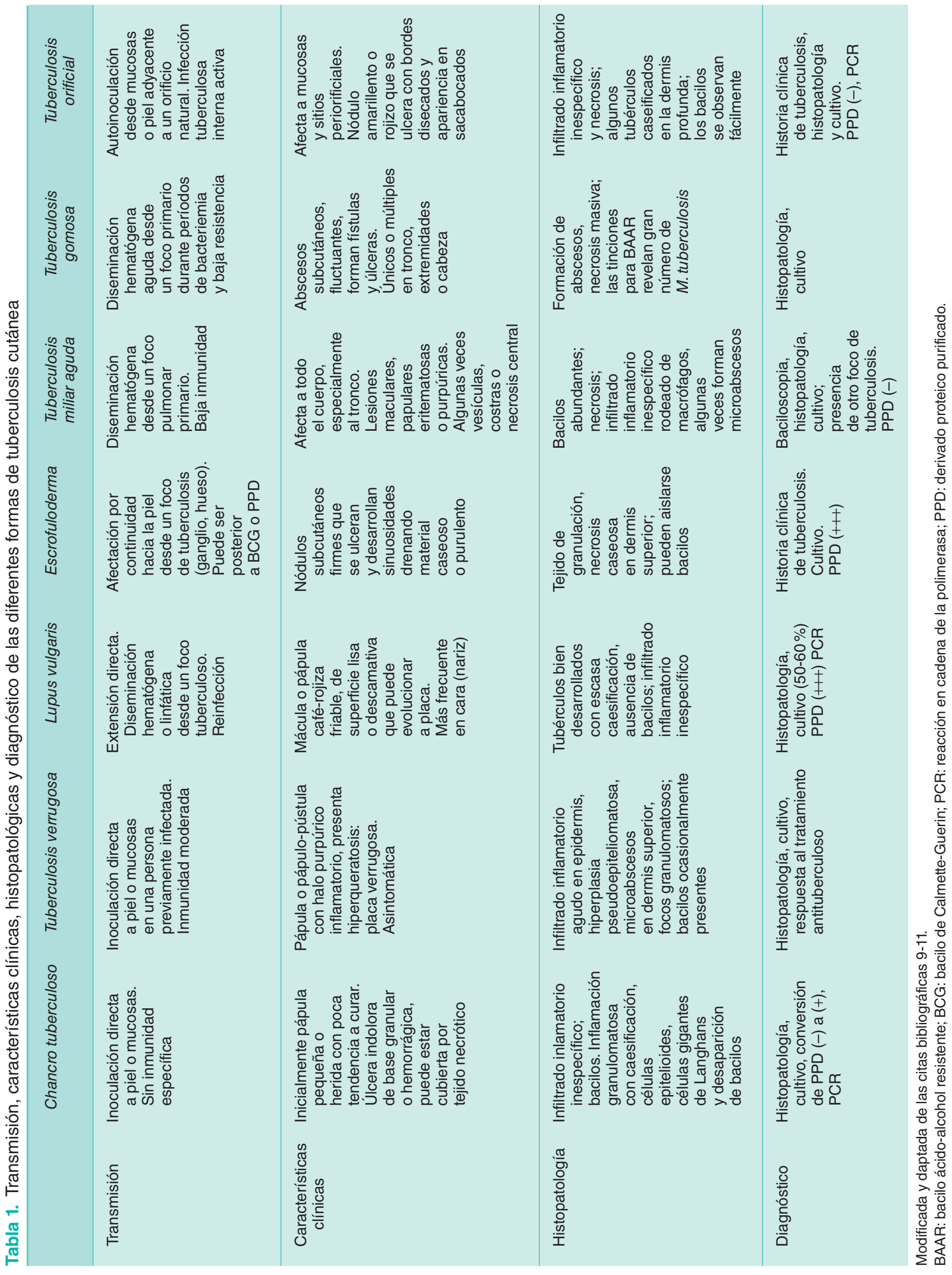


subcutáneos, así como la presencia de pústulas que semejan foliculitis.

\section{Diagnóstico}

El diagnóstico de la enfermedad tuberculosa se basa en 4 parámetros que incluyen el cuadro clínico, el estudio histopatológico, el cultivo y la identificación del ADN mediante la reacción en cadena de la polimerasa (PCR por sus siglas en inglés) ${ }^{14}$. Cada vez se encuentran nuevos métodos que intentan acelerar el diagnóstico de la TB con una sensibilidad y especificidad adecuadas. La mayoría de ellos se enfocan primordialmente al diagnóstico de la TBP, pero podrían ser útiles en las formas extrapulmonares, como la $\mathrm{TBC}^{11,14,15}$.

A continuación revisaremos los diferentes procedimientos diagnósticos más utilizados en la actualidad en la TB en general y su aplicación en la investigación de la TBC.

\section{Diagnóstico histopatológico}

El estudio histopatológico de las biopsias cutáneas revela que las diferentes formas de presentación pueden tener hallazgos similares, pero existen datos característicos que pueden orientar a un tipo específico de $\mathrm{TBC}^{9-11}$. En el caso del chancro tuberculoso, la forma aguda muestra una inflamación neutrofílica con necrosis inespecífica y en ocasiones hay bacilos presentes, mientras que en la forma crónica existen granulomas con caseificación central, células epiteloides, células gigantes de Langerhans y los bacilos suelen estar ausentes. En la TB verrugosa temprana existe inflamación aguda en la epidermis, hiperplasia pseudoepiteliomatosa y microabscesos en la dermis superficial; en ocasiones pueden observarse bacilos y focos granulomatosos. En el escrofuloderma es posible aislar bacilos del pus presente en las lesiones; además, en la dermis profunda se observa caseificación y necrosis. Los bacilos pueden observarse más fácilmente en la forma orificial junto con cambios inespecíficos, como necrosis y caseificación en la dermis profunda. La presencia de tubérculos bien desarrollados con escasa caseificación y cambios inflamatorios inespecíficos y la ausencia de bacilos pueden encontrarse en el lupus vulgaris. La tubeculosis gomosa puede presentar formación masiva de abscesos y necrosis y las tinciones para Mtb suelen revelar gran cantidad de bacilos. Por último, en la TB miliar aguda existen abundantes bacilos, necrosis e infiltrado inflamatorio inespecífico en ocasiones desarrollando microabscesos. El estudio histopatológico es útil, especialmente en el chancro tuberculoso, lupus vulgaris, TB gomosa, TB aguda miliar y en la forma orificial ${ }^{9-13}$.

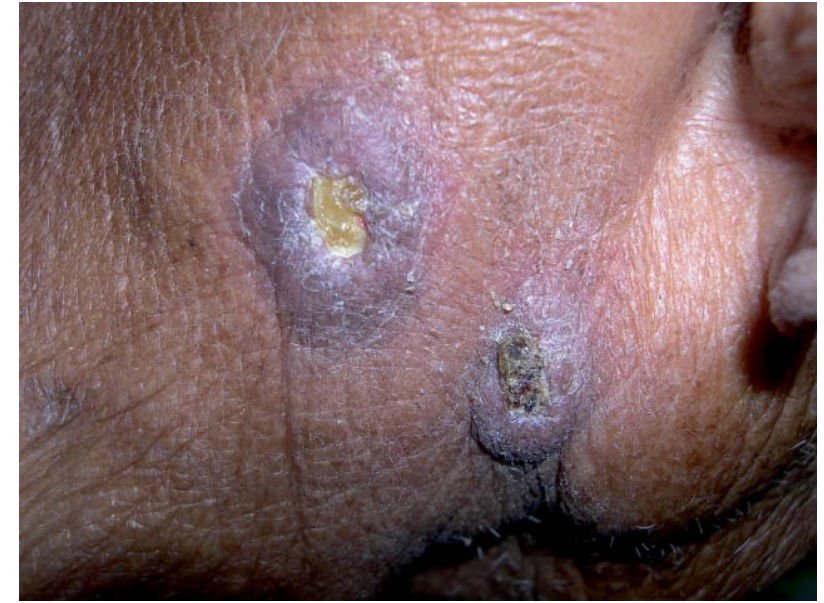

Figura 1. Tuberculosis cutánea de forma verrugosa.

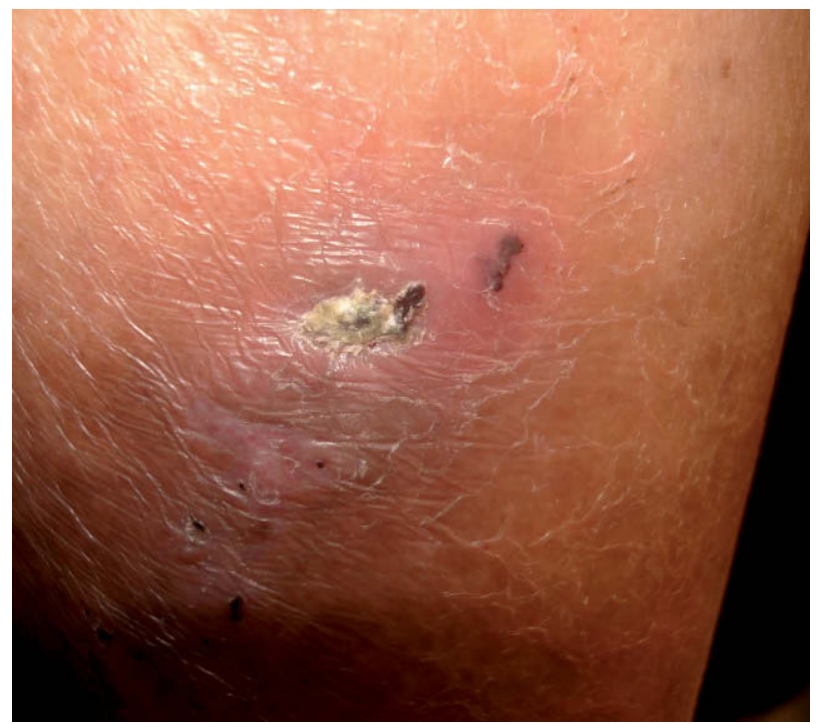

Figura 2. Tuberculosis cutánea en forma de escrofuloderma.

\section{Diagnóstico por pruebas: tinciones y cultivos}

Las micobacterias tienen una pared rica en lípidos complejos que les confieren propiedades características de tinción en el laboratorio. La pared lipídica de los bacilos no permite que una mezcla de alcohol ácido penetre libremente en el interior de la bacteria. De ahí el término de bacilos ácido-alcohol resistentes (BAAR), situación que para nada refleja la vulnerabilidad de la micobacteria a dichas sustancias. La observación de BAAR al microscopio en tinciones de secreciones o tejidos es la primera evidencia de la presencia de micobacterias, sin que necesariamente signifique que se trate de $\mathrm{Mtb}$, pero nos permitirá iniciar el tratamiento empírico en caso de reunir la sospecha clínica suficiente. Otras causas de BAAR positivo son los géneros Nocardia, Corynebacterium, micobacterias no tuberculosas y artefac- 
tos. Las técnicas de tinción incluyen Ziehl-Neelsen, Kinyoun y técnicas fluorocrómicas con auramina-rodamina. La más utilizada es la tinción de Ziehl-Neelsen. Se necesitan $\geq 10^{4}$ bacterias por mililitro para obtener un diagnóstico positivo, por lo que su utilidad es limitada en muestras paucibacilares, hecho habitual en las formas extrapulmonares, como la TBC. La sensibilidad en muestras pulmonares varía de un 40 a un $80 \%$. Por lo anterior se puede concluir que el tener una tinción de BAAR negativa no descarta el diagnóstico de tuberculosis ${ }^{16}$.

El cultivo se considera el estándar de oro para el diagnóstico de TB activa, su sensibilidad y especificidad en muestras pulmonares es del 80 y $99 \%$, respectivamente, pero es significativamente menor en muestras cutáneas. El cultivo de muestras cutáneas es necesario para el diagnóstico, especialmente en aquellos pacientes con sida o que reciben fármacos inmunosupresores, ya que en estos casos las manifestaciones cutáneas y las lesiones histopatológicas suelen ser atípicas. En el lupus vulgaris el cultivo sólo es positivo en el $6 \%$ de los casos ${ }^{1}$. Los medios de cultivo más utilizados para el asilamiento de Mtb son aquellos que tienen como base el huevo (Löwenstein-Jensen [LJ]) y los semisintéticos con agar (7H10 y 7H11 de Middlebrook) ${ }^{6}$. Los cultivos sólidos tradicionales como el LJ tienen la desventaja de demorarse entre 4 a 8 semanas en la obtención de un resultado ${ }^{16}$. El uso de medios líquidos permite acelerar el crecimiento y se han diseñado mecanismos ingeniosos que permiten detectar crecimiento en tiempos tan cortos como en 3 a 7 días. Dentro de estas técnicas de cultivo rápido las más usadas son el BACTEC ${ }^{\circledR}$ en sus versiones radiométrica (BACTEC ${ }^{\circledR} 460$ ) o fluorimétrica $\left(\right.$ BACTEC ${ }^{\circledR} 960 /$ MGIT $^{17}{ }^{17}$. El principio de estas técnicas se basa en la liberación de un marcador (radiactivo o fluorocromo) de un metabolito incluido en el medio de cultivo que es utilizado por la micobacteria. La liberación del marcador puede ser detectada con un equipo especial aun antes de que las colonias de micobacterias sean visibles. Además de la identificación de las diferentes micobacterias es posible hacer pruebas de susceptibilidad a fármacos. En un metanálisis de 10 estudios los sistemas BACTEC ${ }^{\circledR}$ 960/MGIT y BACTEC ${ }^{\circledR} 460$ mostraron una sensibilidad y especificidad para la detección de micobacterias del 81,5 y $99,6 \%$ y del 85,8 y $99,9 \%$ respectivamente ${ }^{17}$. El BACTEC $^{\circledR} 460$ tiene el inconveniente del empleo de radiactividad, haciendo su empleo difícil y complicado. La combinación de 960/MGIT y BACTEC ${ }^{\circledR} 460$ con medio sólido convencional LJ aumenta la sensibilidad a un 87,7 y $89,7 \%$, respectivamente ${ }^{16,17}$. En general, la sensibilidad de los cultivos es mayor que la de la baciloscopia, ya que se requieren muy pocos bacilos para tener un resultado positivo. Se pueden hacer cultivos de las biopsias teniendo cuidado de que estas se conserven en solución salina (no formol) y que idealmente se tomen antes de haber iniciado el tratamiento antituberculoso.
Umapathy et al realizaron un estudio en donde encontraron confirmación bacteriológica (en medio LJ + piruvato + agar 7H11) o histológica en el 88\% de 193 muestras estudiadas para TBC, lo cual se considera un alto porcentaje de positividad ${ }^{18}$.

El medio de cultivo bifásico no radiométrico (MB-SeptiCheck $^{\circledR}$ ) utiliza frascos de $20 \mathrm{ml}$ de caldo $7 \mathrm{H} 12$ a los que se agrega en la parte superior un dispositivo que contiene diferentes medios sólidos. Las ventajas sobre el BACTEC ${ }^{\circledR}$ incluyen mayor sensibilidad y crecimiento sobre la fase sólida para practicar pruebas de identificación, sin la necesidad de hacer resiembras, y sus desventajas implican una detección de crecimiento más lenta y no permite realizar estudios de sensibilidad in vitro ${ }^{6,16,17}$.

El incremento de las infecciones diseminadas por M.avium-intracellulare y Mtb en pacientes con sida ha estimulado el desarrollo de técnicas que permitan su detección en sangre (hemocultivo); las más eficaces son las de lisis-centrifugación y las radiométricas ${ }^{6}$. La principal ventaja de la lisis-centrifugación es que permite cuantificar el número de bacterias por mililitro de sangre y controlar seriadamente la eficacia del tratamiento. El hemocultivo se indica principalmente en pacientes con sida con recuento de linfocitos $\mathrm{CD} 4+<50 / \mu 1$ y fiebre de origen desconocido.

\section{Amplificación de ácidos nucleicos (prueba de reacción en cadena de la polimerasa)}

La amplificación de ácidos nucleicos usando la PCR ha revolucionado la microbiología, facilitando la detección directa y la identificación de agentes infecciosos en muestras clínicas en un período muy corto. La PCR implica la amplificación in vitro de secuencias de ADN específicas del microorganismo y constituye una herramienta prometedora en el diagnóstico de TBP y de varias formas de TBC, especialmente aquellas paucibacilares como el lupus vulgaris y la TB verrugosa ${ }^{19,20}$. Es capaz de demostrar la presencia de fragmentos de ADN micobacterianos en muestras biológicas con resultado negativo en la tinción de Ziehl-Neelsen o en el cultivo, lo que resulta muy útil en infecciones no bacilíferas, en pacientes con cuadros clínicos atípicos asociados a inmunosupresión o a infección por $\mathrm{VIH}^{20,21}$. La PCR genera resultados satisfactorios a partir de 100 bacilos por muestra en cuestión de horas ${ }^{16}$. Sin embargo, esta técnica no está disponible en muchos países, en especial en aquellos en vías de desarrollo.

En estudios previos la utilidad de la PCR ha sido mayor en individuos que presentan lesiones nodulares diseminadas o lesiones ulceradas en el contexto de inmunosupresión y que han demostrado bacilos positivos, por lo que la PCR no se utiliza de rutina ${ }^{22}$. El método de la PCR ofrece un diagnóstico rápido (todo el proceso tarda alrededor de 
5 días), mucho menor que los métodos convencionales antes mencionados ${ }^{8,23}$. La sensibilidad de la PCR ha demostrado ser mejor que el examen directo microscópico y comparable a la del cultivo, especialmente cuando se trata de lupus vulgaris ${ }^{7,8,20}$. Asimismo, es una herramienta útil para diferenciar Mtb de otras especies de micobacterias ${ }^{24}$. La sensibilidad de la PCR se ve limitada cuando se utilizan especímenes BAAR negativos o muestras paucibacilares; en general, se habla de una sensibilidad del $50-72 \%$ en

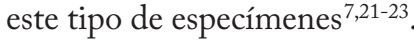

La técnica de la PCR puede realizarse en biopsias en fresco o en tejido fijado en parafina. En este último caso se incrementa la posibilidad de falsos negativos debido a la degradación del ADN durante el proceso de fijación. Se ha sugerido que si se utiliza tejido para la PCR de más de 5 años, se reduce significativamente la amplificación del ADN como resultado de su degradación $n^{17,21,23,24}$.

En un estudio Hsiao et al observaron que en las formas paucibacilares de TBC, con presentación clínica e histopatológica atípica, la $\mathrm{PCR}$ provee una detección rápida y sensible del ADN de Mtb en muestras fijadas en formalina y especímenes fijados en parafina ${ }^{14}$. Asimismo, Senturk et al, en el año 2002, reportaron la eficacia de la PCR para Mtb en tejidos embebidos en parafina, donde concluyeron que la fijación en en este medio disminuye su sensibilidad ${ }^{15}$.

En otro estudio, Salian et al desarrollaron un ensayo basado en tejido (pulmonar y extrapulmonar) fijado en parafina para encontrar Mtb por medio de la PCR. La prueba pudo detectar desde 9 microorganismos en secciones de $5 \mu \mathrm{m}$ fijadas en formalina y embebidas en parafina. De los 135 especímenes estudiados Mtb fue detectado en $11 \mathrm{de}$ ellos que habían sido negativos por BAAR o por cultivo. La PCR dio un falso negativo en una muestra que resultó positiva en el cultivo, y se reportaron 7 falsos positivos que mostraron positividad en el BAAR, pero que no se cultivaron o fueron negativos en el cultivo. Con estos datos los autores concluyen que la PCR es una herramienta útil para detectar la presencia de Mtb en tejidos fijados en formalina y embebidos en parafina ${ }^{24}$.

Se han identificado un considerable número de regiones/secuencias del genoma micobacteriano (por ejemplo IS6110, IS986, $65 \mathrm{kDa}$ y $38 \mathrm{kDa}$ ) como antígenos blanco para la PCR. La mayoría de los estudios han utilizado la secuencia IS6110; sin embargo, también se ha reportado que hasta un $40 \%$ de las muestras del sur de la India carecen de una o más copias de este antígeno. El antígeno proteico b o Pab $(38 \mathrm{kDa})$ es una lipoproteína de transporte de fosfatasa serodominante en humanos, y se ha utilizado en aquellas muestras pulmonares y extrapulmonares en las que otras regiones o secuencias no han sido de ayuda para esclarecer el diagnóstico ${ }^{25-27}$.

La Food and Drug Administration (FDA) de Estados Unidos de América autorizó el uso clínico y la comerciali- zación de tres pruebas diferentes de PCR: Mycobacterium tuberculosis direct test (Gen-Probe MTD), Enhanced MTD y el Amplicor Mycobacterium tuberculosis test. Todas ellas se aprobaron para el estudio de TBP. Según los datos de la FDA la sensibilidad de estas pruebas para diagnosticar TBP comparadas con el cultivo es del $95 \%$ en pacientes con BAAR positivo, pero sólo del $50 \%$ en pacientes con BAAR negativo. La especificidad es superior al $95 \%$ en ambas, sean BAAR positivo o negativo ${ }^{6,16}$. Sin embargo, se llegó a la conclusión de que estas pruebas no resultaron ser tan exitosas como se esperaba, y que no sustituyen a las baciloscopias o cultivos. Se desconoce aún si estas pruebas pueden aplicarse a especímenes cutáneos y si serán o no de utilidad.

\section{Prueba de la tuberculina}

Esta prueba pone de manifiesto la primoinfección en el paciente por medio de un estado de hipersensibilidad del organismo frente a las proteínas del bacilo tuberculoso. Se utiliza primordialmente para apoyar el diagnóstico de sospecha de TB o para detectar una infección tuberculosa latente. Resulta positiva tras la infección por Mtb, aunque también puede serlo en caso de vacunación con el bacilo de Calmette-Guerin (BCG) o infección por micobacterias ambientales oportunistas ${ }^{6,28}$. La prueba de la tuberculina se realiza inyectando $5 \mathrm{U}(0,1 \mathrm{ml})$ de derivado proteico purificado (PPD) de froma intradérmica en la cara anterior del antebrazo y se considera positiva al obtener una induración visible y palpable en el sitio de la inoculación superior a $10 \mathrm{~mm}$ de diámetro; puede acompañarse de edema, eritema, vesiculación y en ocasiones necrosis y linfadenitis regional ${ }^{28}$. La lectura se realiza a las 72 horas de la aplicación, midiendo el diámetro de la induración en milímetros, transversal al eje longitudinal del antebrazo. En pacientes con infección por el VIH una lectura $\geq 5 \mathrm{~mm}$ se considera positiva; así, en los sujetos sin factores de riesgo y con antecedentes de vacunación con BCG una induración $\geq 15 \mathrm{~mm}$ debe considerarse positiva. Se estima que la reacción a la tuberculina es negativa en un elevado porcentaje de casos de sujetos positivos para el VIH, oscilando entre el 30 y el $50 \%$.

La positividad de la prueba de la tuberculina o PPD no indica una infección activa, ya que también será positiva en casos de infección latente o infección previa ${ }^{6,28}$. La prueba de la tuberculina está indicada en todos los casos en que interese confirmar o descartar la infección tuberculosa y no haya contraindicaciones para la misma. Sin embargo, su interpretación depende de factores tales como la inmunosupresión del paciente y la técnica de aplicación. Los resultados falsos negativos pueden observarse en infecciones sistémicas graves, incluyendo la propia TB, y estados de inmunosupresión. 


\section{Cromatografía}

La principal utilidad de esta prueba es la identificación de las diferentes especies de micobacterias una vez que se tiene un cultivo positivo. Las micobacterias poseen una pared celular muy rica en lípidos, y los ácidos micólicos son característicos de este género. Estos pueden separarse con relativa facilidad en ésteres metílicos por cromatografía en capa fina en gel de sílice. La identificación definitiva se realiza por cromatografía de gases. La utilidad de esta técnica en la TBC es muy limitada 6 .

\section{Serología y otros estudios inmunológicos}

Los métodos serológicos prometían ser un procedimiento diagnóstico muy útil cuando se empezaron a utilizar hace más de 100 años. Los antígenos empleados se obtenían por métodos físico-químicos y los resultados fueron desalentadores. La serología evolucionó y aparecieron las pruebas de ensayo inmunoabsorbente ligado a enzima o EnzymeLinked ImmunoSorbent Assay (ELISA) en $1976^{29}$, que emplea antígenos altamente purificados ${ }^{16,25,26}$.

En la actualidad se han analizado una serie de antígenos con mejores resultados, entre los que se encuentran las proteínas de Ag-60, 30kDa, 38kDa, Ag-60, complejo $45 / 47 \mathrm{kDa}, \mathrm{Kp} 90$, el antígeno DPEP o MPT32, el antígeno Mtb81 y el más reciente ESAT-6 ${ }^{29-34}$. Los resultados de la serología pueden variar en relación con la naturaleza del antígeno, la pureza del mismo, la técnica usada (ELISA directa o indirecta), el sistema de detección, el estadio de la TB, si el paciente es bacilífero o no, si la afección es extrapulmonar y las condiciones asociadas, como infección por el VIH ${ }^{25,26}$. La sensibilidad, usando los antígenos individuales, varía entre un $60-80 \%$ con especificidades de 84-100\%. La combinación de antígenos en la misma prueba puede aumentar la sensibilidad, pero disminuye la especificidad ${ }^{35-37}$. Ejemplos de estas combinaciones son el TbF6 (102kDa), poliproteína fusionada compuesta por 4 antígenos $(38 \mathrm{kDa}, \mathrm{Mtb} 8, \mathrm{Mtb} 11$ y Mtb48) y el $T b F 10(55 \mathrm{kDa})$, que es una fusión de tres antígenos (38kDa con Mtb8 y Mtb11). Aunque se dispone de paquetes comerciales de uso sencillo, la detección de anticuerpos no ha podido posicionarse como una prueba rutinaria de diagnóstico.

En la era de los nuevos desarrollos tecnológicos, recientemente se han introducido en el mercado dos pruebas inmunológicas que inicialmente se destinaban al diagnóstico de la TB latente, pero que ahora se promueven para el estudio de casos activos: QuantiFERON ${ }^{28,37}$ y el ELISpot ${ }^{38,39}$. Ambas se basan en la producción de interferón (IFN)- $\gamma$ antígeno específico por células $\mathrm{T}$ en respuesta a los antígenos ESAT-6 y CFP-10 de Mtb ${ }^{40-43}$. Esto sólo ocurre cuando los linfocitos $\mathrm{T}$ tienen memoria inmunológica generada por la infección previa con Mtb. QuantiFERON es un método actualmente aprobado por la FDA para el diagnóstico de la TB latente. Su sensibilidad y especificidad son del 89 y 99\%, respectivamente. Por otro lado, ELISpot presenta una sensibilidad del $98,8 \%$ y una especificidad del $100 \%{ }^{6,44}$. Estas pruebas tienen la ventaja de requerir sólo una muestra sanguínea y el resultado se obtiene en uno o dos días. Para QuantiFERON ya existen paquetes comerciales muy sencillos de usar. La lectura de la reacción, producción de IFN- $\gamma$, se hace mediante ELISA. Los procedimientos empleados en ELISpot, aunque usan el mismo principio, son más laboriosos. Se requiere la extracción de células para cultivarlas con los antígenos. El alto coste es el principal inconveniente de estas dos pruebas. Su principal ventaja es que discriminan muy bien aquellos sujetos que tienen vacunación con $\mathrm{BCG}$, lo cual es un problema común. Mientras que el resultado cualitativo no discrimina entre infección latente o activa, el cuantitativo permite detectar enfermedad (infección activa).

La adenosín desaminasa (ADA) es una enzima del catabolismo de las purinas. Se distribuye ampliamente en el organismo humano, pero su mayor actividad se encuentra en el tejido linfoide, fundamentalmente en los linfocitos $\mathrm{T}$. Su principal utilidad es su determinación en el derrame de pacientes con TB pleural. Tiene una alta sensibilidad, pero una especificidad limitada. Sus niveles se elevan también en empiemas, linfomas, enfermedades autoinmunes y cán$\mathrm{cer}^{45}$. Asimismo se ha utilizado en líquido de peritonitis, pericarditis y líquido cefalorraquídeo de origen tuberculoso. Su aplicación en el diagnóstico de la TBC es irrelevante.

Para mejorar la especificidad en el diagnóstico serológico de la TB es necesario utilizar antígenos específicos de Mtb y evitar la posible contaminación bacteriana durante el proceso de purificación. Algunos autores sugieren la combinación de antígenos específicos de Mtb purificados para incrementar la sensibilidad del serodiagnóstico de la $\mathrm{TB}^{44}$. En conclusión, el diagnóstico serológico de la TB no puede recomendarse para uso general, y aún se desconoce su utilidad en casos de TB extrapulmonar.

\section{Conclusiones}

La TB en todas sus formas continúa siendo un problema universal de salud, así como un reto para el desarrollo de herramientas diagnósticas que provean un resultado específico, sensible, rápido y accesible para el paciente.

Los nuevos métodos diagnósticos utilizados en la actualidad se han enfocado en la TBP; se desconoce si alguno de estos pudiera tener alguna aplicación en las formas extrapulmonares, especialmente en la TBC. Para ello hace falta la aplicación de los mismos a casos de TBC, lo cual puede resultar difícil por la baja incidencia de ésta. 
La realización del estudio histopatológico y el aislamiento de Mtb en especímenes cutáneos por cultivo o por PCR se consideran, hasta el momento, las mejores herramientas diagnósticas para la detección y el diagnóstico de la TBC.

El criterio absoluto de TBC lo dicta el asilamiento del bacilo en el cultivo o la identificación de ADN micobacterial por PCR. Desafortunadamente, son pocas las instituciones o laboratorios que pueden costear tal procedimiento, en especial en los países en vías de desarrollo.

\section{Conflicto de intereses}

Declaramos no tener ningún conflicto de intereses.

\section{Bibliografía}

1. Alianza Alto a la Tuberculosis y Organización Mundial de la Salud.Plan Mundial para Detener la Tuberculosis 2006-2015. Ginebra: Organización Mundial de la Salud; 2006 (WHO/HTM/STB/2006,35).

2. Fariña MC, Gegundez MI, Piqué E, Esteban J, Martín L, Requena L, et al. Cutaneous tuberculosis: a clinical, histopathologic, and bacteriologic study.J Am Acad Dermatol.1995; 33:433-40.

3. Sàbat M, Ribera M, Casanova JM, Bielsa I, Fuente MJ, Ferrándiz C. Carcinoma epidermoide sobre lupus vulgar. Actas Dermosifiliogr. 2003;94:616-9.

4. Kivanc-Altunay I, Baysal Z, Ekmekci TR, Koslu A. Incidence of cutaneous tuberculosis in patients with organ tuberculosis. Int J Dermatol. 2003;42:197-200.

5. Roche E, García Melgares ML, Vilata JJ, Fortea JM. Escrofuloderma de larga evolución. Actas Dermosifiliogr. 2005;96: 522-4.

6. Caminero JA, Casal M, Auxina V, Pina JM, Sauret J. Recomendaciones SEPAR. Diagnóstico de la tuberculosis. Arch Bronconeumol. 1996;32:85-99.

7. Diagnostic Standards and Classification of Tuberculosis in Adults and Children. This Official Statement of the American Thoracic Society and the Centers for Disease Control and Prevention was adopted by the ATS Board of Directors, July 1999. This Statement was endorsed by the Council of the Infectious Disease Society of America, September 1999. Am J Respir Crit Care Med. 2000;161 4 Pt 1:1376-95.

8. Pai M, Ramsay A, O'Brien R. Evidence-based tuberculosis diagnosis. PLoS Med. 2008;5:e156. Disponible en: Doi:10.1371/journal.pmed.0050156.

9. Tappeiner G, Wolff K. Tuberculosis and other mycobacterial infections. En: Freedberg IM, Eisen AZ, Wolff K, Austen KF, Goldsmith LA, Katz SI, editors. Fitzpatrick's Dermatology in General Medicine. 6th ed. EE.UU.: McGraw-Hill; 2003. p. 1933-49.

10. Ramos-e-Silva M, Ribeiro de Castro MC. Mycobacterial infections. En: Bolognia JL, Jorizzo JL, Rapini RP, editors. Dermatology. Philadelphia: Mosby; 2003. p. 1145-64.

11. Tincopa Wong OW, Sánchez Saldana L. Tuberculosis cutánea. Dermatol Peru. 2003;13:195-214.

12. Varas C, Eguino P, Gardeazabal J, Diaz-Pérez JL. Tuberculosis cutánea en cicatriz quirúrgica. Actas Dermosifiliogr. 2003;94:412-3.
13. Serra Guillén C, Requena C, Alfaro A, Hueso L, Nagore E, Botella Estrada R, et al. Lupus vulgar de 50 años de evolución. Actas Dermosifiliogr. 2005;96:376-8.

14. Pa-Fan H, Chin-Yuan T, Hsiu-Chin C, Hsin-Yi S. Polymerase chain reaction based detection of Mycobacterium in tissues showing granulomatous inflammation without demonstrable acid-fast bacilli. Int J Dermatol. 2003;42:281-6.

15. Senturk N, Sahin S, Kocagoz T. Polymerase chain reaction in cutaneous tuberculosis: is it a reliable diagnostic method in paraffin-embedded tissues? Int J Dermatol. 2002;41:863-6.

16. Zenteno Cuevas R. Pasado, presente y futuro de las técnicas diagnósticas de tuberculosis. Rev Inst Nal Enf Resp Mex. 2003;16:181-6.

17. Cruciani MC, Scarparo M, Malena O, Bosco G, Serpelloni C. Mengoli C. Meta-analysis of BACTEC MGIT 960 and BACTEC $460 \mathrm{~TB}$, with or without solid media, for detection of mycobacteria.J Clin Microbiol. 2004;42:2321-5.

18. Umapathy KC, Begum R, Ravichandran G, Rahman F, Paramasivan CN, Ramanathan VD. Comprehensive findings on clinical, bacteriological, histopathological and therapeutic aspects of cutaneous tuberculosis. Trop Med Int Health. 2006;11:1521-8.

19. Tan SH, Tan BH, Goh CL, Tan KC, Tan MF, Ng WC, et al. Detection of Mycobacterium tuberculosis DNA using polymerase chain reaction in cutaneous tuberculosis and tuberculids. Int J Dermatol. 1999;38:122-7.

20. Loera-Castañeda V, Sánchez-Corona J, Morán-Moguel MC.El papel de las técnicas de biología molecular en el diagnóstico y control de tuberculosis. Gac Med Mex. 2003;3: 288-90.

21. Welsh O, Vera-Cabrera L, Fernández-Reyes M, Gómez M, Ocampo-Candiani J. Cutaneous tuberculosis confirmed by PCR in three patients with biopsy and culture negative for Mycobacterium tuberculosis. Int J Dermatol. 2007;46:734-5.

22. Ramam M, Rashimi M, Ramesh V. How soon does cutaneous tuberculosis respond to treatment? Implications for a therapeutic test of diagnosis. Int J Dermatol. 2005;44:121-4.

23. Ena P, Sechi LA, Saccabusi S, Molicotti P, Lorrai MP, Siddi $\mathrm{M}$, et al. Rapid identification of cutaneous infections by nontubercular mycobacteria by polymerase chain reaction-restriction analysis length polymorphism of the hsp65 gene. Int J Dermatol. 2001;40:495-9.

24. Salian N, Rish J, Husain M, Eisenach K, Cave D, Rendón A, et al. Detection of Mycobacterium tuberculosis in formalin-fixed, paraffin-embedded tissue using a polymerase chain reaction. Am J Respir Crit Care Med. 1996;153:1419-23.

25. Houghton RL, Lodes MJ, Dillon DC, Reynolds LD, Day $\mathrm{CH}, \mathrm{McNeill} \mathrm{PD}$, et al. Use of multiepitope polyproteins in serodiagnosis of active tuberculosis. Clin Diagn Lab Immunol. 2002;9:883-91.

26. Amor YB, Shashkina E, Johnson S, Bifani PJ, Kurepina N, Kreiswirth B, et al. Immunological characterization of novel secreted antigens of Mycobacterium tuberculosis. Scand J Immunol. 2005;61:139-46.

27. Negi SS, Anand R, Basir SF, Pasha ST, Gupta S, Khare S, et al. Protein antigen $\mathrm{b}(\mathrm{Pab})$ based PCR test in diagnosis of pulmonary \& extra-pulmonary tuberculosis. Indian J Med Res. 2006;124:81-8.

28. Desai AM, Hsu S. Medical pearl: interpretation of tuberculin skin test in patients who have received the $B C G$ vaccine. J Am Acad Dermatol. 2005;53:868-9. 
29. Mazurek GH, Jereb J, Lobue P, Iademarco MF, Metchock B, Vernon A. Guidelines for using the QuantiFERON-TB Gold test for detecting Mycobacterium tuberculosis infection, United States. MMWR Recomm Rep. 2005;54:49-55.

30. Meier T, Eulenbruch HP, Wrighton-Smith P, Enders G, Regnath T. Sensivity of a new commercial enzyme-linked immunospot assay (T SPOT-TB) for diagnosis of tuberculosis in clinical practice. Eur J Clin Microbiol Infect Dis. 2005;24:529-36.

31. Skjøt RLV, Oettinger T, Rosenkrands I, Ravn P, Brock I, Jacobsen S, et al. Comparative evaluation of low molecular mass proteins from Mycobacterium tuberculosis identifies members of the ESAT- 6 family as immunodominant T cell antigens. Infect Immun. 2000;68:214-20.

32. Pathan AA, Wilkinson KA, Klenerman P, McShane $H$, Davidson RN, Pasvol G, et al. Direct ex vivo analysis of antigen-specific IFN- $\boldsymbol{\gamma}$-secreting CD4 T cells in Mycobacterium tuberculosis-infected individuals: associations with clinical disease state and effect of treatment. J Immunol. 2001; 167:5217-25.

33. Pollock J, Andersen P. The potential of the ESAT-6 antigen secreted by virulent mycobacteria for specific diagnosis of tuberculosis. J Infect Dis. 1997;175:1251-4.

34. Ravn P, Munk ME, Andersen AB, Lundgren B, Lundgren JD, Nielsen LN, et al. Prospective evaluation of a whole-blood test using Mycobacterium tuberculosis-specific antigens ESAT- 6 and CFP-10 for diagnosis of active tuberculosis. Clin Diagn Lab Immunol. 2005;12:491-6.

35. Mori T, Sakatani M, Yamagishi F, Takashima T, Kawabe Y, Nagao K, et al. Specific detection of tuberculosis infection: an interferon-gamma-based assay using new antigens. Am J Respir Crit Care Med. 2004;170:59-64.

36. Mustafam AS, Oftung F, Amoudy HA, Madi NM, Abal AT, Shaban F, et al. Multiple epitopes from the Mycobacterium tuberculosis ESAT-6 are recognized by antigen-specific human T cell lines. Clin Infect Dis. 2000;30 Suppl 3: S201-S5.
37. Pinxteren L, Ravn P, Agger E, Pollock J, Andersen P. Diagnosis of tuberculosis based on two specific antigens ESAT-6 and CFP-10. Clin Diagn Lab Immunol. 2000;7: 155-60.

38. Pai M, Riley LW, Colford JM Jr. Interferon-gamma assays in the immunodiagnosis of tuberculosis: a systematic review. Lancet Infect Dis. 2004;4:761-76.

39. Hill PC, Brookes RH, Fox A, Jackson-Sillah D, Jeffries DJ, Lugos MD, et al. Longitudinal assessment of an ELISPOT test for Mycobacterium tuberculosis infection. PLoS Med. 2007;4:e192.

40. Diel R, Loddenkemper R, Meywald-Walter K, Niemann S, Nienhaus A. Predictive value of a whole-blood IFN- $\gamma$ assay for the development of active TB disease. Am J Respir Crit Care Med. 2008;177:1164-70.

41. Dosanjh DP, Hinks TS, Innes JA, Deeks JJ, Pasvol G, Hackforth S, et al. Improved diagnostic evaluation of suspected tuberculosis. Ann Intern Med. 2008;148:325-36.

42. Ferrara G, Losi M, D’Amico R, Roversi P, Piro R, Meacci M, et al. Use in routine clinical practice of two comercial blood tests for diagnosis of infection with Mycobacterium tuberculosis. Lancet. 2006;367:1328-34.

43. Van-Lume DSM, de Souza JR, Melo WG, Melo VL, Cabral M ML, Rego JC, et al. Preliminary results in the immunodiagnosis of tuberculosis in children based on T cell responses to ESAT-6 and PPD antigens. Mem Inst Oswaldo Cruz [online]. 2008;103:401-4.

44. Julián E, Matas L, Pérez A, Alcaide J, Lanéelle MA, Luquin M. Serodiagnosis of tuberculosis: comparison of Immunoglobulin A (IgA) response to sulfolipid I with IgG and IgM responses to 2,3-diacyltrehalose, 2,3,6-triacyltrehalose, and cord factor antigens. J Clin Microbiol. 2002;40:3782.

45. Coitinho C, San Martín R, Mier C, Rodríguez R, Zuzino Torres S, Rivas C. Utilidad de la dosificación de adenosin deaminasa en el diagnóstico de la tuberculosis pleural. Primera experiencia nacional. Rev Med Urug. 2007;23:19-24. 